\title{
Determination of Coccidiostats (Amprolium and Decoquinate) in Cattle and Chicken's Muscle using High Performance Liquid Chromatography
}

\author{
ByungJu Kim, ${ }^{\dagger}$ Hyunsun Ham, ${ }^{\dagger}$ Jin-Joo Lee, ${ }^{\dagger}$ Nam-Yong Cheong, ${ }^{\dagger, \dagger}$ and Seung-Woon Myung ${ }^{\dagger, *}$ \\ ${ }^{\dagger}$ Department of Chemistry, Kyonggi University, Suwon 443-760, Korea. *E-mail: swmyung@kgu.ac.kr \\ ${ }^{\star}$ Korea Apperal Testing and Research Institute, Seoul, Korea \\ Received May 12, 2011, Accepted December 13, 2011
}

\begin{abstract}
An analytical method for the simultaneous determination of veterinary medicines (amprolium and decoquinate) in cattle and chicken's muscle by HPLC/UV-vis was established. Samples were extracted by a HLB (Hydrophilic-Liphophilic Balance) cartridge with acetonitrile and methanol. Prior to HPLC injection, a mixture solvent (Water:MeOH, 1:1) was utilized as a reconstitution solvent. Chromatographic separation was achieved with a C18 column $(250 \times 4.6 \mathrm{~mm}, 5 \mu \mathrm{m})$ using gradient elution with $20 \mathrm{mM} \mathrm{HFBA}$ and MeOH:ACN (1:1.8). The calibration curves from the spiked blank matrix showed good linearity (above $r^{2}=0.997$ ) in the concentration range of $0.13-12.0 \mathrm{mg} \mathrm{kg}^{-1}$. The relative recovery (accuracy) and limit of quantitation (LOQ) were in the range of $78.5-107.1 \%$ and $0.13-0.42 \mathrm{mg} \mathrm{kg}^{-1}$, respectively. The developed method can be used to determine under the MRL (Maximum Residue Limits) levels of veterinary medicines in animal tissues.
\end{abstract}

Key Words : Coccidiostats, Amprolium, Decoquinate, HPLC, Simultaneous determination

\section{Introduction}

Coccidiosis is an infectious disease caused by several species of Eimeria protozoa, which cause intestinal cell disruption, resulting in weight loss or poor weight gain. ${ }^{1}$ Therefore, attention has been paid to the prevention and treatment of this disease, especially in large intensive farms where economical losses are the most substantial. Coccidiostats, such as amprolium and decoquinate, are registered as veterinary drugs for the treatment of the clinical form of coccidiosis. $^{2}$ Amprolium and decoquinate stop the growth of new protozoa and kills them as well. ${ }^{3}$ These coccidiostats are an anticoccidial feed additive approved for use in feeds for broiler chickens, cattle and calves, sheep, and goats, and they are approved for use in the prevention of coccidiosis in ruminating and nonruminating calves, including veal calves and cattle, caused by Eimeria protozoa. ${ }^{4}$

However, continuous administration of coccidiostats often leads to the accumulation of veterinary drug residues in food products for human consumption. ${ }^{5,6}$ The presence of residue of veterinary drugs has received much attention because of the growing concern for safety by consumers. The Korea Food and Drug Administration established maximum residue limits (MRLs) in chicken and cattle's muscle for the amprolium $(0.5 \mathrm{mg} / \mathrm{kg})$ and decoquinate $(2.0 \mathrm{mg} / \mathrm{kg})$.

Therefore, a sensitive and selective analytical methodology is required to detect such low concentrations of these compounds in cow and chicken matrices. Several methods based on fluorescence or UV-detection with post-column derivatization have been reported for analysis of the drugs. Most of the methods available for determining amprolium are based on ion-pair liquid chromatography, mainly using heptafluorobutyric acid and ultraviolet detection. ${ }^{7-10}$ And the recent published methods for the determination of residue

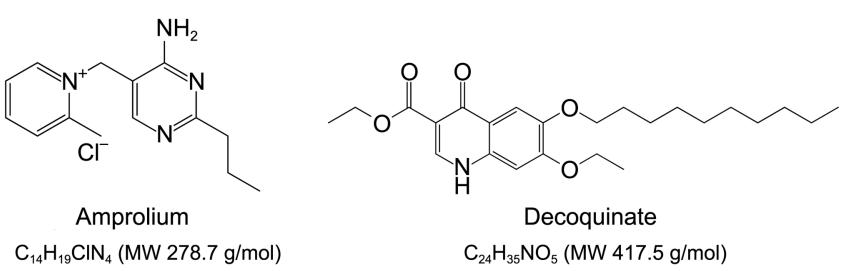

Figure 1. Chemical structures of amprolium and decoquinate.

levels of coccidiostats employ the LC-MS/MS technique, because using mass spectrometry for detection allows better sensitivity and covers a wider range of analytes. However, at the same time, conventional HPLC has advantages, such as fitness for the intended application, low cost, and suitability for routine laboratories not equipped with sophisticated instruments. Notably, because of the different physicochemical properties (Fig. 1), the opposite solubility of amprolium and decoquinate in water and organic solvents, such as methanol and acetonitrile, enabled the determination of a single class of compounds or only single analytes.

Thus, a sensitive and reliable simultaneous HPLC method for amprolium and decoquinate determination in animal muscle has not been described yet. Therefore, this study was designed to develop and validate an analytical technique and sample preparation using SPE for the simultaneous analysis of residual amprolium and decoquinate in chicken and cattle's muscle. Additionally, the effective separation technique of thiamine, which is an endogenous interference for amprolium analysis in animal tissue, is described.

\section{Experimental}

Reagents, Materials, and Instruments. Amprolium and decoquinate were prepared with high purity reagents pur- 
chased from Sigma-Aldrich (St Louis, MO, USA). Organic solvents, such as methanol, acetonitrile, chloroform, and acetone, were obtained from J. T. Baker (Phillipsburg, NJ, USA) and those reagents were HPLC grade. Heptafluorobutyric acid (HFBA) that obtained from Sigma-Aldrich (St Louis, MO, USA) was of a high purity reagent. Amprolium and decoquinate working standard solutions were prepared by dissolving them in distilled water and chloroform $(1000 \mu \mathrm{g}$ $\mathrm{mL}^{-1}$ and $200 \mu \mathrm{g} \mathrm{mL} L^{-1}$, respectively), respectively, and they were stored in a refrigerator $\left(-20^{\circ} \mathrm{C}\right)$. Before use, these working standard solutions were intentionally diluted with water and methanol.

The glassware used for this experiment was washed by washing solvent, methanol, and a mixture of acetone and distilled water, and then dried. Polypropylene conical tubes were obtained from Falcon (Austin, Texas, USA). The supra $22 \mathrm{~K}$ centrifuge was obtained from Han-Il Scientific Co. Ltd. (Seoul, Korea) and centrifuge tube $(50 \mathrm{~mL})$ was obtained from Nalgene (New York, USA). GF/B glass filter paper was obtained from Whatman (Maidstone, UK), and syringe disc filter $(0.45 \mu \mathrm{m}$ and $13 \mathrm{~mm})$ was obtained from Life Sciences (Watford, UK). The SPE cartridge for the extraction of the analyte was an Oasis HLB (HydrophilicLipophilic Balance, $200 \mathrm{mg}, 6 \mathrm{cc}$ ) which was purchased from Waters (Milford, Massachusetts, USA) and the vacuum manifold was obtained from Supelco (Bellefonte, PA, USA). The concentrator was a TurboVap LV nitrogen concentrator which was obtained from Caliper Lifescience (Seattle, WA, USA), and the vortex mixer was obtained from Vision Scientific (Bucheon, Korea).

An Agilent 1100 series HPLC system (Palo Alto, CA, USA) equipped with a binary pump was connected to an Agilent G1313A autosampler and G1313A UV-Vis detector. The analytical column was a reverse-phase CAPCELL PAK C18 column $(250 \mathrm{~mm} \times 4.6 \mathrm{~mm}, 5 \mu \mathrm{m}$ particle size $)$. Mobile phase A (20 mM HFBA in water) and phase B (methanol: acetonitrile $=1: 1.8$ ) were used with a flow rate of $1.0 \mathrm{~mL} /$ $\mathrm{min}$. The separation was achieved with the following linear gradient system: at $0 \min \mathrm{A}: \mathrm{B}=55: 45(\mathrm{v} / \mathrm{v}), 5 \min \mathrm{A}: \mathrm{B}=$ $55: 45,9 \min \mathrm{A}: \mathrm{B}=5: 95,18 \mathrm{~min} \mathrm{~A}: \mathrm{B}=5: 95$, and $18.5 \mathrm{~min}$ $\mathrm{A}: \mathrm{B}=5: 95$, A 10 min post-time allowed for re-equilibration of the column. The injection volume was $20 \mu \mathrm{L}$. Analytes were detected with the DAD set at $262 \mathrm{~nm}$.

Sample Preparation. Samples, $10 \mathrm{~g}$ of cattle or chicken's muscle, were prepared in Polypropylene conical tubes (50 $\mathrm{mL}$ ) and then homogenized using a mechanical homogenizer. When the solutes (amprolium and decoquinate) were spiked, the $1000 \mu \mathrm{g} \mathrm{kg}^{-1}$ of standard solution (in water and chloroform) was spiked in this step. To extract the analyte, $10 \mathrm{~mL}$ of acetonitrile was added to each homogenized sample and was shaken for $30 \mathrm{~min}$ at $250 \mathrm{rpm}$. Then, centrifugal separation was used for $15 \mathrm{~min}$ at $3500 \mathrm{rpm}$ in order to collect the upper layer. The supernatant was mixed with 1 $\mathrm{mL}$ of distilled water. The mixture solvent was vaporized down to $1 \mathrm{~mL}$ by using a nitrogen evaporator at $60{ }^{\circ} \mathrm{C}$ and then $4 \mathrm{~mL}$ of distilled water was added. An Oasis HLB (200 $\mathrm{mg}, 6 \mathrm{cc}$ ) cartridge was connected to a vacuum manifold and

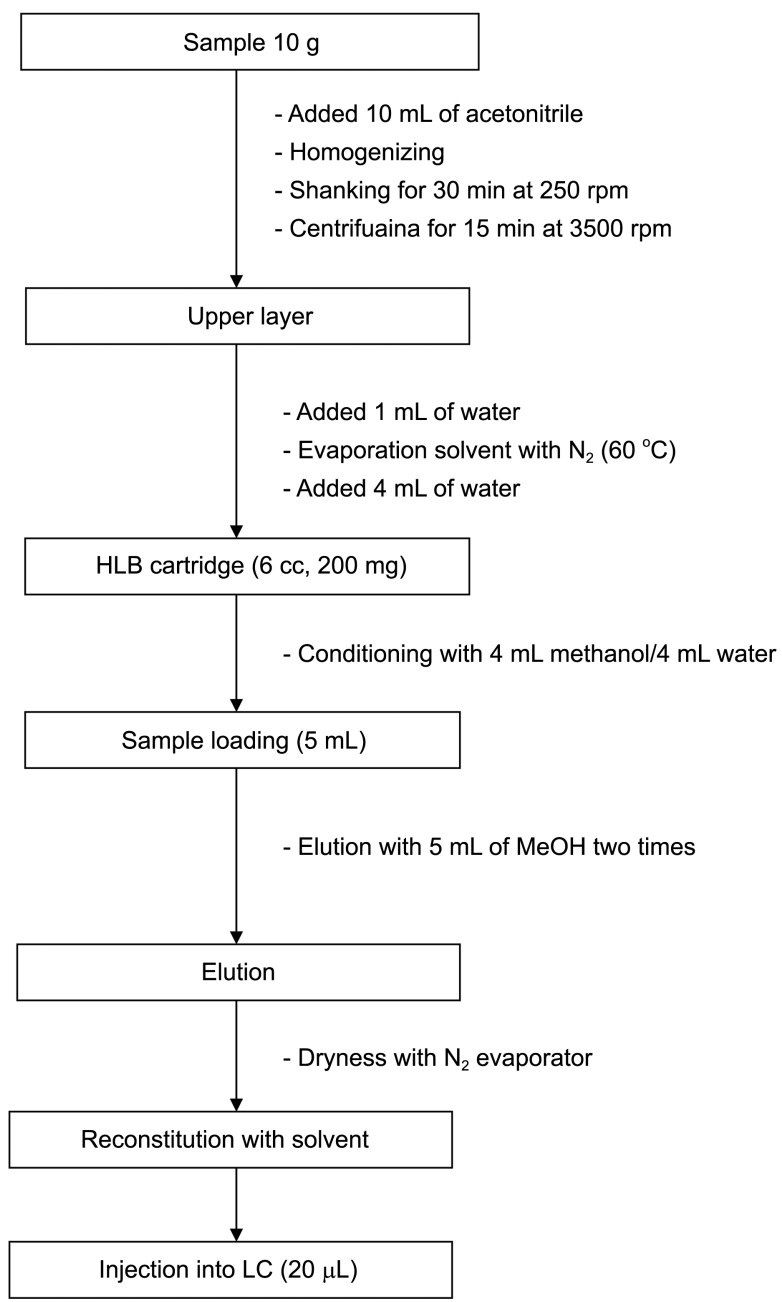

Figure 2. Schematic flow diagram of the sample preparation for the analysis of amprolium and decoquinate from chicken and cattle's muscle.

conditioned by a solution of $4 \mathrm{~mL}$ methanol and $4 \mathrm{~mL}$ distilled water and then $5 \mathrm{~mL}$ of the sample was loaded into the cartridge. The sample was eluted with $5 \mathrm{~mL}$ methanol (two times) and the eluent was completely vaporized by nitrogen evaporator at $60^{\circ} \mathrm{C}$. The residue was dissolved with $200 \mu \mathrm{L}$ of solvent and then filtrated through a disc filter of $0.45 \mu \mathrm{m}$ to be analyzed by LC/UV-vis (Fig. 2).

\section{Results and Discussion}

Chromatographic Separation. It is difficult to retain amprolium and decoquinate, which have different physicochemical properties, in reversed-phase mode simultaneously. Therefore, a chromatographic mode based on the ion pair mode was performed. Heptafluorobutyric acid was used as an ion-pair reagent to facilitate the retention of both drugs in the reversed-phase mode.

After mixed standard solution was injected into HPLC system, chromatogram was obtained. As shown in Figure 3, amprolium was eluted within the first $6.93 \mathrm{~min}$, and decoquinate was detected at $16.42 \mathrm{~min}$, so the analytes were effectively separated simultaneously using the reversed-phase 


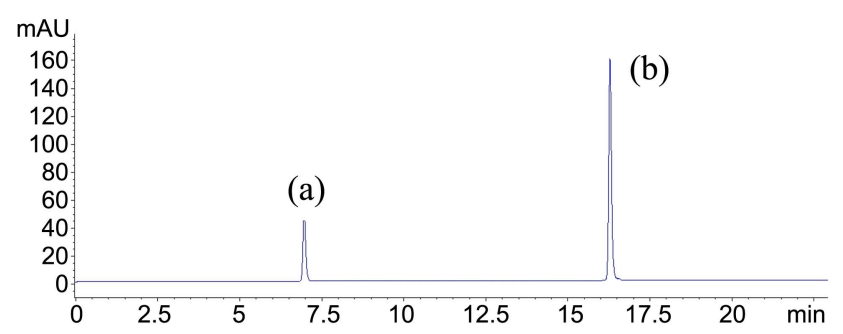

Figure 3. HPLC chromatogram of (a) amprolium and (b) decoquinate standard mixture.

liquid chromatographic system without any derivatization procedure. Concentration of sample in Figure 3 was $1 \mathrm{mg} \mathrm{kg}^{-1}$ and chromatographic conditions are described in the experimental section.

Optimization of Volume of Extraction Solvent and Shaking Time. At first, the effects of the solvent volume and shaking time were investigated. The choice of extraction solvent volume and shaking time were performed by extracting a spiked sample. From the previous experiences and SPE compatibility, acetonitrile was chosen as an extraction solvent. Because of the distribution of analyte between the solvent and sample, the volume of the extraction solvent and shaking time utilized to extract analytes from samples affect the extraction yield. The volume of the solvent (shaking time was $30 \mathrm{~min}$ and acetonitrile was used as a solvent) was varied among 5, 10, 15, and $20 \mathrm{~mL}$ and the shaking time varied among 10, 20, 30, and $40 \mathrm{~min}$. It was found that the recovery of the amprolium was affected little by the solvent volume, but decoquinate's recovery increased up to $86.4 \%$ when $10 \mathrm{~mL}$ was used, and the recovery was not changed above $10 \mathrm{~mL}$ (Fig. 4). As the shaking time (at $10 \mathrm{~mL}$ of

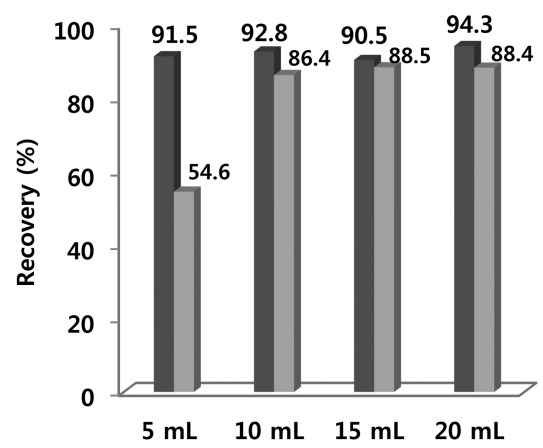

Amprolium

Decoquinate

Figure 4. Effect of extraction solvent volume.

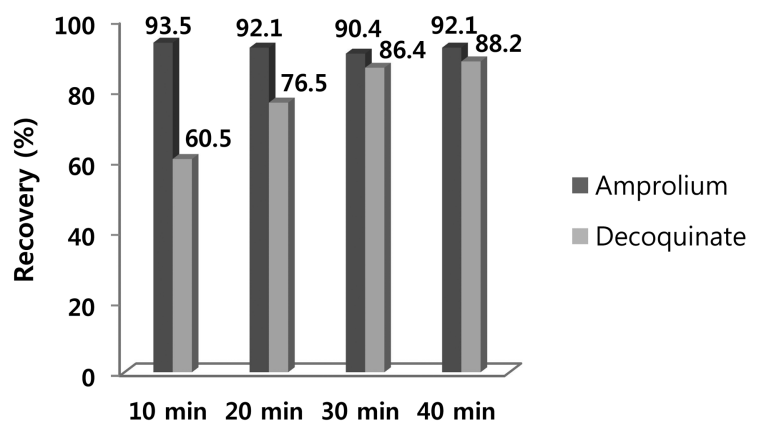

Figure 5. Effect of shaking time of amprolium and decoquinate. solvent volume) increased, the amprolium recovery was not changeed, but the extraction yield of decoquinate increased (Fig. 5). These could be explained by the differences of the solubility and distribution for the solvent. Because decoquinate has a hydrophobic nature, it was difficult to extract from muscle and required more solvent. Consequently, 10 $\mathrm{mL}$ of extraction solvent volume and 30 minute of shaking time were chosen as optimized parameters.

Optimization of Elution Solvent Volume. Generally, the extracted solvent from a sample contains matrix components, causing interference in recovery and chromatographic separation. Methanol was chosen as a satisfactory solvent for the elution and cleanup of the loaded sample on an Oasis HLB cartridge. The volume of elution solvent was tested to show its efficiency in the elution of amprolium and decoquinate from muscle samples. The criteria for a successful method are better recovery. The good recovery of analytes from exhausted extract, depending on the solubility of the targeted compounded in the solvent, was used to evaluate the extractive process. Data from Figure 6 shows that the recovery of amprolium and decoquinate were $77.4 \%$ and $42.5 \%$ in 3 $\mathrm{mL}$ of elution solvent, respectively. The recoveries increased as a function of the volume of elution solvent, but recovery of both drugs from $10 \mathrm{~mL}$ to $15 \mathrm{~mL}$ shows only a small increment ( $93.4 \%$ to $94.1 \%$ and $88.3 \%$ to $90.2 \%$ ), and the 10 $\mathrm{mL}$ solvent run shows better precision than the $15 \mathrm{~mL}$ run. And then $10 \mathrm{~mL}$ of the elution solvent was selected as a criterion for further experimentation.

Optimization of Reconstitution Solvent and pH. After extraction and cleanup, the dried residue should be re-

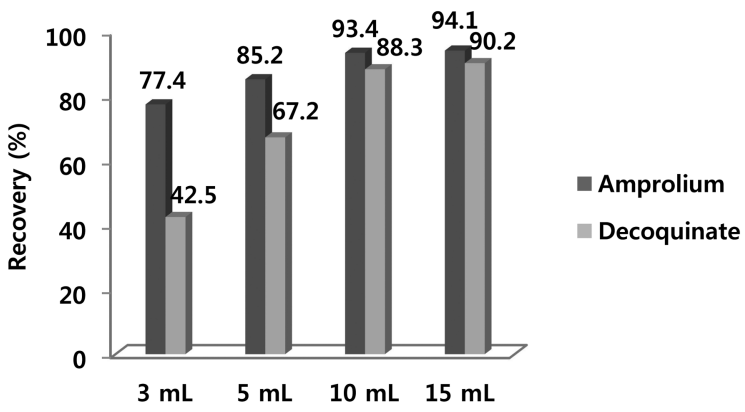

Figure 6. Effect of volume of elution solvent.

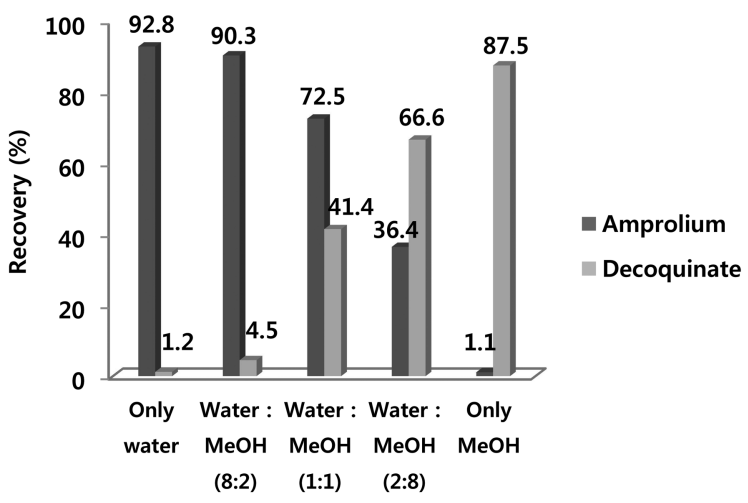

Figure 7. Effect of reconstitution solvent. 
constituted with a suitable solvent prior to injection into the LC system. The reconstitution solvent affects the recovery from the HPLC column and consequently shows the results of the overall recovery. Amprolium is very soluble in water and slightly soluble in methanol, but decoquinate is the opposite (Fig. 7). From the results, amprolium exhibited the highest recovery in water and the lowest recovery in methanol, and in contrast decoquinate exhibited the opposite results. This may be explained by the fact that the solubility of analytes in the reconstitution solvent affects the behavior of amprolium and decoquinate in the HPLC chromatographic system. The equal mixed solution of methanol and water $(1: 1)$ exhibited appropriate recoveries for both drugs (72.5\% for amprolium and $41.4 \%$ for decoquinate). Despite the losses, this solvent mixture was chosen for the simultaneous determination testing (sample preparation and instrumental analysis). The recoveries were sufficient to detect up to the maximum residual limits (MRLs) levels from the chicken and cattle's muscle. Although the mixture solvent $(\mathrm{MeOH}$ :water $=1: 1)$ may be used as a reconstitution solvent for screening, water and methanol are appropriate for the effective quantification of amprolium and decoquinate, respectively.

Also, the effect of $\mathrm{pH}$ was investigated, but the behavior of both drugs was nearly independent of $\mathrm{pH}$ the of the reconstitution solvent (Fig. 8).

Effective Separation of Amprolium and Thiamine. Thiamine or thiamin, also known as vitamin B1, has a similar chemical structure with amprolium and plays an important role in helping the body metabolize carbohydrates and fat to produce energy. Thiamine is concentrated in muscle tissue and it may interfere with the analysis of amprolium from cattle and chicken's muscle. Thiamine could not be removed during the extraction and purification process and was eluated closely in the HPLC analysis. ${ }^{11}$ For the effective separation from amprolium in chromatography, several organic phases were investigated and the MeOH:ACN (1:1.8) mixture yielded a well-resolved chromatogram (Fig. 9).

Method Validation. Sample preparation was performed for amprolium and decoquinate by an established solid phase extraction. Limits of Detection (LOD) and Limits of Quantification (LOQ) for spiked blank muscle were measured based on the LC/UV-vis analysis.

The measurement method for LOD and LOQ are dis-

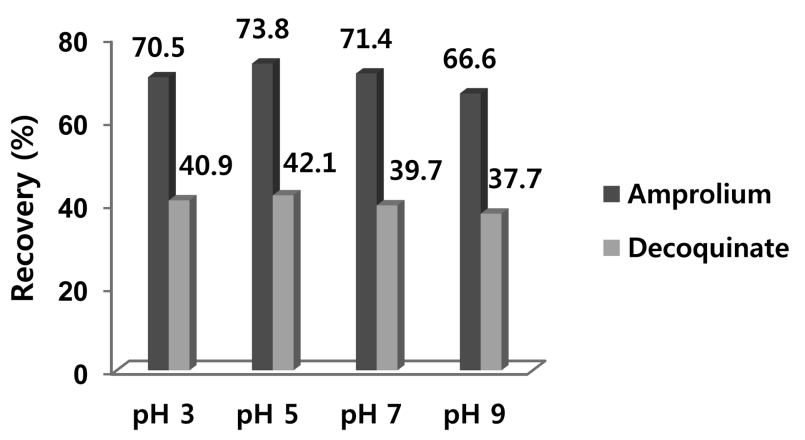

Figure 8. Effect of reconstitution solvent $\mathrm{pH}$.

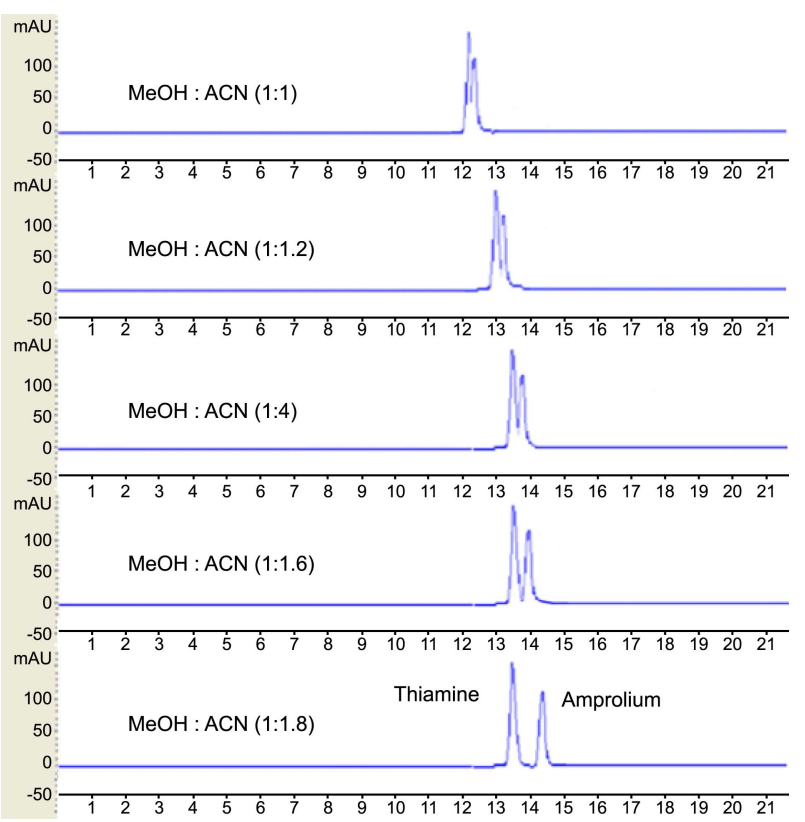

Figure 9. HPLC chromatograms for separation of amprolium and thiamine.

cussed below. The LOD was assumed from the instrumental analysis process and the sample $(\mathrm{n}=7)$ was prepared at a concentration within 1-5 times of the LOD. After the standard deviation $(\sigma)$ was calculated using the results from 7 replicate experiments and the slope $(\mathrm{m})$ of the linear calibration curve was calculated, the LOD and LOQ were set at $3 \sigma / \mathrm{m}$ and $10 \sigma / \mathrm{m}$, respectively. As a result, the LOD and LOQ of amprolium in cattle and chicken's muscle were in the concentration range of $0.04 \sim 0.05 \mathrm{mg} \mathrm{kg}^{-1}$ and $0.13 \sim 0.18 \mathrm{mg} \mathrm{kg}$, respectively. The LOD and LOQ of decoquinate in cattle and chicken's muscle were in the concentration range of $0.12 \sim 0.13 \mathrm{mg} \mathrm{kg}^{-1}$ and $0.38 \sim 0.42 \mathrm{mg}$ $\mathrm{kg}^{-1}$ respectively. The LOQs were above the MRL in chicken and cattle's muscle.

The survey was performed in the concentration level of LOQ $\sim 6$ times of MRLs. The accuracy and precision (as a $\mathrm{RSD} \%$ ) of amprolium in the concentration range of 0.13-3.0 $\mathrm{mg} \mathrm{kg}^{-1}$ from the spiked muscles was $96.6-102.8 \%$ and $2.2-$ $7.9 \%$, respectively. The accuracy and precision (as a RSD\%) of decoquinate in the concentration range of $0.38-12.0 \mathrm{mg}$ $\mathrm{kg}^{-1}$ from the spiked muscles was $78.5-107.1 \%$ and $4.7-$ $10.9 \%$, respectively. The results were well within the recommended acceptable values of $-30 \%$ to $+20 \%$ at each

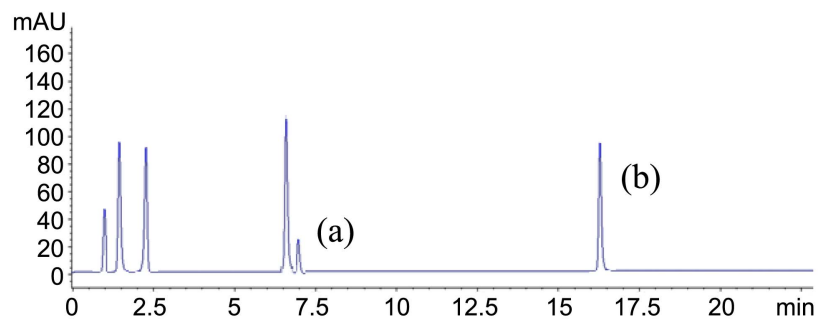

Figure 10. HPLC chromatogram of (a) amprolium and (b) decoquinate in real sample. 
Table 1. LODs, LOQs, accuracy, and precision for the amprolium and decoquinate

\begin{tabular}{|c|c|c|c|c|c|c|}
\hline Compound & Matrix & $\begin{array}{c}\mathrm{LODs}^{a} \\
(\mathrm{mg} / \mathrm{kg})\end{array}$ & $\begin{array}{c}\mathrm{LOQs}^{b} \\
(\mathrm{mg} / \mathrm{kg})\end{array}$ & $\begin{array}{l}\text { Conc. } \\
(\mathrm{mg} / \mathrm{kg})\end{array}$ & $\begin{array}{c}\text { Accuracy } \\
(\%)\end{array}$ & $\begin{array}{c}\text { Precision } \\
(\%) \\
(n=5)\end{array}$ \\
\hline \multirow{12}{*}{ Amprolium } & \multirow{6}{*}{ Cattle } & \multirow{6}{*}{0.04} & \multirow{6}{*}{0.13} & 0.13 & 99.7 & 3.8 \\
\hline & & & & 0.25 & 101.8 & 3.1 \\
\hline & & & & 0.5 & 98.8 & 3.5 \\
\hline & & & & 1.0 & 101.9 & 3.1 \\
\hline & & & & 2.0 & 98.3 & 3.8 \\
\hline & & & & 3.0 & 100.6 & 6.1 \\
\hline & \multirow{6}{*}{ Chicken } & \multirow{6}{*}{0.05} & \multirow{6}{*}{0.18} & 0.18 & 90.0 & 7.9 \\
\hline & & & & 0.25 & 96.6 & 5.4 \\
\hline & & & & 0.5 & 102.8 & 7.1 \\
\hline & & & & 1.0 & 101.1 & 7.0 \\
\hline & & & & 2.0 & 100.8 & 2.2 \\
\hline & & & & 3.0 & 99.5 & 7.1 \\
\hline \multirow{12}{*}{ Decoquinate } & \multirow{6}{*}{ Cattle } & \multirow{6}{*}{0.12} & \multirow{6}{*}{0.38} & 0.38 & 78.5 & 4.7 \\
\hline & & & & 1.0 & 106.0 & 9.9 \\
\hline & & & & 2.0 & 98.6 & 8.8 \\
\hline & & & & 4.0 & 107.1 & 8.2 \\
\hline & & & & 8.0 & 94.7 & 5.7 \\
\hline & & & & 12.0 & 101.6 & 10.9 \\
\hline & \multirow{6}{*}{ Chicken } & \multirow{6}{*}{0.13} & \multirow{6}{*}{0.42} & 0.42 & 98.6 & 10.5 \\
\hline & & & & 1.0 & 94.5 & 9.4 \\
\hline & & & & 2.0 & 101.9 & 8.9 \\
\hline & & & & 4.0 & 101.5 & 8.3 \\
\hline & & & & 8.0 & 102.0 & 6.1 \\
\hline & & & & 12.0 & 98.8 & 7.6 \\
\hline
\end{tabular}

${ }^{a}$ LODs (Limits of Detection): $3 \sigma / \mathrm{m} .{ }^{b} \mathrm{LOQs}$ (Limits of Quantitation): $20 \%<\mathrm{RSD} \%$ and $10 \mathrm{\sigma} / \mathrm{m} .{ }^{c}$ Accuracy: (Measured value/Calculated value) $\times 100$

Table 2. Working range, linear equation, and $\mathrm{R}^{2}$ for amprolium and decoquinate

\begin{tabular}{|c|c|c|c|c|}
\hline Compounds & Matrix & $\begin{array}{l}\text { Working } \\
\text { range } \\
(\mathrm{mg} / \mathrm{kg})\end{array}$ & Linear equation & $\mathrm{R}^{2}$ \\
\hline \multirow{2}{*}{ Amprolium } & Cattle & $0.13-3.0$ & 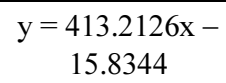 & 0.9997 \\
\hline & Chicken & $0.18-3.0$ & $\begin{array}{c}\mathrm{y}=376.8236 \mathrm{x}+ \\
14.1688\end{array}$ & 0.9998 \\
\hline \multirow{2}{*}{ Decoquinate- } & Cattle & $0.38-12.0$ & $\begin{aligned} \mathrm{y}= & 444.9281 \mathrm{x}+ \\
& 39.1446\end{aligned}$ & 0.9970 \\
\hline & Chicken & $0.42-12.0$ & $\begin{aligned} \mathrm{y}= & 602.2585 \mathrm{x}+ \\
& 27.9470\end{aligned}$ & 0.9993 \\
\hline
\end{tabular}

concentration level (Table 1).

For analyzing the residual analytes in samples, the samples were spiked with standard solutions of 0.13 (or
0.18 , in chicken), $0.25,0.5,1.0,2.0$ and $3.0 \mathrm{mg} \mathrm{kg}^{-1}$ for amprolium, 0.38 (or 0.42 in chicken), 1.0, 2.0, 4.0, 8.0 and $12.0 \mathrm{mg} \mathrm{kg}^{-1}$ for decoquinate and then the analytes were extracted by the established analytical condition in order to be analyzed by LC/UV-vis. The calibration curves were obtained from the external standard method and the corresponding correlation coefficients for both drugs and matrices were reasonable because they were above $r^{2}=0.997$ (Table 2).

\section{Conclusion}

A sensitive, reliable, and reproducible simultaneous analytical method has allowed the detection of amprolium and decoquinate in cattle and chicken's muscle using HPLC/ UV-vis.

In cattle and chicken, the LOD and LOQ of amprolium were in the concentration range of $0.04-0.05 \mathrm{mg} \mathrm{kg}^{-1}$ and $0.13-0.18 \mathrm{mg} \mathrm{kg}^{-1}$, respectively, and the intraday precision and accuracy for the spiked samples were 2.2-7.9 RSD\% and $90.0-102.8 \%$, respectively. The LOD and LOQ of decoquinate from cattle and chicken samples were $0.12-0.13$ $\mathrm{mg} \mathrm{kg}-1$ and $0.38-0.42 \mathrm{mg} \mathrm{kg}^{-1}$, respectively. The established method satisfied the maximum residue limits (MRLs) of the Korean Food Code and it has been applied to the analysis of the veterinary drugs by government and private laboratories.

Acknowledgments. This study was conducted with the support of the National Institute of Food and Drug Safety Evaluation (NIFDS) of Korea under the requested object, "A study on an analytical method for residual veterinary drugs". This work was supported by Kyonggi University Research Assistant Fellowship 2011.

\section{References}

1. Squadrone, S.; Mauro, C.; Ferro, G. L.; Amato, G.; Abete, M. C. J. Pharm. Biomed. Anal. 2008, 48, 1457.

2. Olejnik, M.; Szprengier-Juszkiewicz, T.; Jedziniak, P. J. Chromatogr. A 2009, 1216, 8141 .

3. Peters, J. E.; Derijcke, J.; Verlinden, M.; Wyffels, R. Avian Dis. 1994, 38, 483

4. Sanchez, A. A.; Campbell, H. M. J. AOAC Int. 2008, 91, 685.

5. Reig, M.; Toldra, F. Meat Sci. 2008, 78, 60.

6. Girardi, C.; Odore, R. Vet. Res. Commun. 2008, 32, S11.

7. Tan, H. S. I.; Ramachandran, P.; Caccini, W. J. Pharm. Biomed. Anal. 1996, 15, 259.

8. Song, W.; Huang, M.; Rombeiha, W.; Li, H. Rapid Commun. Mass Spectrom. 2007, 21, 1944.

9. Hamanoto, K.; Koike, R.; Shirakura, A.; Sasaki, N.; Machida, Y. J. Chromatogr. B 1997, 693, 489.

10. Furusawa, N. J. Chromatogr. Sci. 2002, 40, 355.

11. Commission Directive 1999/27/EC, 1999. 